\title{
ARTICLE Slow-release delivery enhances the pharmacological properties of oral 5-hydroxytryptophan: mouse proof-of-concept
}

Jacob P. R. Jacobsen ${ }^{1}$, Adrianna Oh ${ }^{1}$, Rachel Bangle ${ }^{1}$, Wendy L. Roberts ${ }^{1}$, Elizabeth L. Royer ${ }^{1}$, Nathan Modesto ${ }^{1}$, Sonora A. Windermere ${ }^{1}$, Zixuan Yi $\mathbb{D}^{1}$, Rebecca Vernon ${ }^{1}$, Manuel Cajina ${ }^{2}$, Nikhil M. Urs ${ }^{3}$, Joshua C. Snyder ${ }^{1}$, Peter J. Nicholls ${ }^{1}$, Benjamin D. Sachs ${ }^{4}$ and Marc G. Caron ${ }^{1,5,6}$

5-hydroxytryptophan (5-HTP) has shown therapeutic promise in a range of human CNS disorders. But native 5-HTP immediate release (IR) is poorly druggable, as rapid absorption causes rapid onset of adverse events, and rapid elimination causes fluctuating exposure. Recently, we reported that 5-HTP delivered as slow-release (SR) in mice augmented the brain pro-serotonergic effect of selective serotonin reuptake inhibitors (SSRIs), without the usual adverse events associated with 5-HTP IR. However, our previous study entailed translational limitations, in terms of route, dose, and duration. Here we modeled oral 5-HTP SR in mice by administering 5-HTP via the food. We modeled oral SSRI treatment via fluoxetine in the water, in a regimen recapitulating clinical pharmacokinetics and pharmacodynamics. 5-HTP SR produced plasma 5-HTP levels well within the range enhancing brain 5-HT function in humans. 5-HTP SR robustly increased brain 5-HT synthesis and levels. When administered with an SSRI, 5-HTP SR enhanced 5-HT-sensitive behaviors and neurotrophic mRNA expression. 5-HTP SR's pro-serotonergic effects were stronger in mice with endogenous brain 5-HT deficiency. In a comprehensive screen, 5-HTP SR was devoid of overt toxicological effects. The present preclinical data, appreciated in the context of published 5-HTP clinical data, suggest that 5-HTP SR could represent a new therapeutic approach to the plethora of CNS disorders potentially treatable with a pro-serotonergic drug. 5-HTP SR might in particular be therapeutically relevant when brain $5-\mathrm{HT}$ deficiency is pathogenic and as an adjunctive augmentation therapy to SSRI therapy.

Neuropsychopharmacology (2019) 44:2082-2090; https://doi.org/10.1038/s41386-019-0400-1

\section{INTRODUCTION}

5-hydroxytryptophan (5-HTP) is the endogenous rate-limiting precursor of 5-hydroxytryptamine (5-HT, serotonin) [1, 2]. In humans and animals, orally administered 5-HTP can reach the brain and enhance brain 5-HT function [3,4]. Clinical pilot trials suggest that adjunctive (additive) 5-HTP augments the antidepressant efficacy of serotonin reuptake inhibitors [see referenes [5-7]]. There are also clinical reports that 5-HTP alleviates for example pain, obesity, and ataxia [8-10]. The human safety record of 5-HTP is good, with no reports of serious adverse events [reviewed in [2, 11]]. Overall, 5-HTP has shown therapeutic promise in a range of CNS disorders.

5-HTP has never been pursued as a therapeutic beyond the experimental stage. This is likely because fast pharmacokinetics makes 5-HTP impractical as a drug: 5-HTP's short half-life, $2 \mathrm{~h}$ [12], entails intermittent pharmacological effect and 5-HTP's rapid absorption entails maximal plasma level-related ( $C_{\text {Max }}$-related) gastrointestinal (Gl) adverse events [13]. However, slow-release (SR) drug delivery can provide sustained drug exposure and lower $C_{\text {Max. }}$ In humans, SR delivery may markedly enhance efficacy and/or safety of fast pharmacokinetics compounds [14, 15]. Thus, it is conceivable that SR delivery could impart therapeutic properties on 5-HTP
Indeed, in mouse models, we recently reported that SR delivery markedly enhanced the therapeutic properties of 5-HTP [3]. SR delivery eliminated the typical GI and CNS adverse events associated with 5-HTP administration in rodents and, surprisingly, enabled higher safe 5-HTP plasma levels. Adjunctive 5-HTP SR potently augmented SSRI-induced $5-\mathrm{HT}_{\text {Ext }}$-elevation, recapitulating human 5-HTP findings [4]. While encouraging, this recent data set had translational limitations: 5-HTP SR was administered parenterally and sub-acutely and the SSRI dose was supra-clinical, saturating, and not selective for the serotonin transporter (SERT). In contrast, in humans a 5-HTP SR drug would be oral and administered chronically and therapeutic SSRI dosing is non-saturating and SERT-selective.

The present study expands on the former; but, employs methodological approaches better translating to a clinical scenario. The aim of the present study was to explore the pharmacokinetics, pharmacodynamics, safety, and thus druggability of oral 5-HTP SR. The aim was not to test oral 5-HTP SR in animal models of CNS disease. Substantial clinical evidence already suggests that an appropriate 5-HTP drug could treat various CNS diseases. Clinical efficacy evidence supersedes any animal disease model data-particularly for psychiatric disorders, where animal disease models are minimally predictive of human

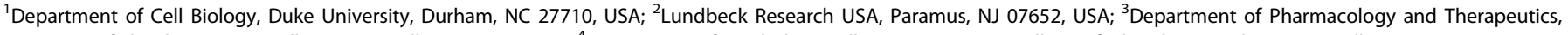

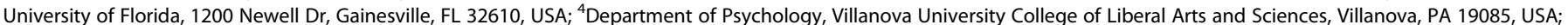
${ }^{5}$ Department of Medicine, Duke University, Durham, NC 27710, USA and ${ }^{6}$ Department of Neurobiology, Duke University, Durham, NC 27710, USA Correspondence: Marc G. Caron (marc.caron@duke.edu) 
efficacy [16, 17]. The present study addressed the following questions in mouse models:

Can oral 5-HTP SR safely elevate plasma 5-HTP to pharmacologically active levels?

Can oral 5-HTP SR safely be combined with therapeuticallyrelevant SSRI treatment?

Can oral 5-HTP SR enhance brain 5-HT synthesis and levels?

Can oral 5-HTP SR, alone or adjunctive to an SSRI, enhance indicators of increased brain 5-HT function?

Will oral 5-HTP SR, alone or adjunctive to an SSRI, have differential effects under conditions of brain 5-HT deficiency?

Answering these questions in animals can inform whether an oral 5-HTP SR treatment would be feasible in humans.

\section{MATERIALS AND METHODS}

Animals

Mice were housed 3-5/cage with food and water available ad libitum on a $12 \mathrm{~h}$ light-dark cycle at $21 \pm 1^{\circ} \mathrm{C}$. All experiments, except sexual behaviors, used female age-matched littermate wild type (WT) and tryptophan hydroxylase $2{ }^{\mathrm{Arg}} 439^{\mathrm{His}}$ knockin mice (3-6-months-old). The latter mice, henceforth referred to as " $5-\mathrm{HT}_{\text {Hypo }}$ " mice, synthesize $20-30 \%$ of WT brain 5 -HT levels $[18,19]$. We used the $5-\mathrm{HT}_{\mathrm{Hypo}}$ mice to model naturalistic brain 5 -HT deficiency. Experiments were conducted in accordance with the National Institutes of Health guidelines for the care and use of animals and an approved protocol from the Duke University Animal Care and Use Committee.

\section{Materials}

Fluoxetine was from Sequoia Research Products (Pangbourne, UK). 5-HTP was from EMD Millipore (Billerica, MA). 5-HT, 5-HIAA, and dopamine were from Sigma (St Louis, MO). Flesinoxan was a gift from Lundbeck (Valby, DK). All chemicals used were of analytical grade.

\section{SSRI treatment}

Chronic SSRI treatment was modeled by fluoxetine in the drinking water, $25 \mathrm{mg} / \mathrm{L}$, corresponding to $\sim 4 \mathrm{mg} / \mathrm{kg} /$ day (assuming a water intake of $150 \mathrm{~mL} /$ day). Pilot studies found chronic fluoxetine 25

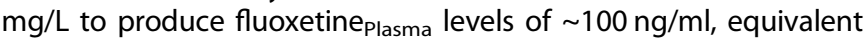
to average clinical levels (Fig. 1a). Fluoxetine water in darkened bottles was changed twice weekly. Fluoxetine Plasma $_{\text {was }}$ determined using HPLC-MS as described [20]. SERT occupancy after fluoxetine treatment was determined ex vivo on brain slices as described [3]. 5-HT $T_{1 A}$ receptor agonist hypothermia was assessed essentially as described [18], but using flesinoxan $(3.3 \mathrm{mg} / \mathrm{kg}$, I.P., in saline $/ 10 \%$ DMSO) as the $5-\mathrm{HT}_{1 \mathrm{~A}}$ receptor agonist. In brief, three baseline and eight post-injection core body temperature readings were recorded in $15 \mathrm{~min}$ intervals. Temperature change was expressed as change from the average of the three baseline measurements.

\section{5-HTP treatments}

Oral 5-HTP SR was modeled by dietary 5-HTP, $6.7 \mathrm{mg} / \mathrm{g}$ chow, equivalent to $\sim 1000 \mathrm{mg} / \mathrm{kg} /$ day [21], and was commenced following 2 weeks of fluoxetine/control treatment (Fig. 1g). This was the highest 5-HTP dose the mice would eat (not shown). Control mice received standard chow (See Supplementary Methods for details). Adjunctive oral 5-HTP immediate release (IR) was modeled by oral gavage, $100 \mathrm{mg} / \mathrm{kg}$ (in saline, $10 \mathrm{ml} / \mathrm{kg}$ ), following 2 weeks of fluoxetine treatment. Gavage with saline served as control.

Tissue and plasma sample collection

All mice were sacrificed at Zeitgeber time $0\left(\mathrm{ZT}_{0}\right)$ by cervical decapitation. Heads were instantly cooled to $0{ }^{\circ} \mathrm{C}$. Whole brains were extracted, frozen on dry ice, and stored at $-80^{\circ} \mathrm{C}$. Later, at $-20^{\circ} \mathrm{C}$, the frontal cortex (orbit anterior to corpus callosum) was dissected, and from $1 \mathrm{~mm}$ thick brain slabs were punched $(1.5 \mathrm{~mm}$ punches) the hippocampus (2 punches) and the nucleus accumbens (1 punch). One centimeter of jejunum was collected $1 \mathrm{~cm}$ below the distal duodenum. Plasma was prepared from trunk blood within $60 \mathrm{~min}$ of collection. For diurnal plasma 5-HTP Plasma assessment during oral 5-HTP SR, $15 \mu \mathrm{l}$ tail-vein blood was collected as described [3] at $\mathrm{ZT}_{0}, \mathrm{ZT}_{6}, \mathrm{ZT}_{12}$, and $\mathrm{ZT}_{18}$. For 5 -HTP Plasma assessment following oral 5-HTP IR, $15 \mu$ lail-vein blood was collected, at $0,15,30,45$, and 60 min post-gavage. All samples were stored at $-80^{\circ} \mathrm{C}$.

$5-\mathrm{HT}_{\text {Ext }}$ sensitive behaviors

All tests were performed between $\mathrm{ZT}_{1}$ and $\mathrm{ZT}_{6}$. Marble burying was performed as described [18]. In novelty suppressed feeding (NSF) the mice were presented for 5 days with one peanut butter chip (Reese's, Hershey, PA) in a $2^{\prime \prime} \times 2^{\prime \prime}$ plastic dish, one chip per mouse in a cage. On day 6 , one chip in a dish was presented in a white, novel arena $\left(20^{\prime \prime} \times 30^{\prime \prime}\right)$. Latency to eat was scored blind from videos, cut-off $600 \mathrm{~s}$.

Physiological toxicology

Diarrhea was scored blindly on a scale from 0 (none) to 3 (severe), as described [3]. For adjunctive oral 5-HTP SR, diarrhea was scored after 2 days and 7 days at $\mathrm{ZT}_{1}$. For 5 -HTP IR, diarrhea was scored 0-30 min after gavage. Head-twitches were counted from videos by a blinded observer. For adjunctive oral 5-HTP SR, head-twitches were counted over 5 min after 2 and 7 days at ZT . For 5 -HTP IR, head-twitches were counted 0-30 min after gavage. Body weights were recorded weekly.

\section{Behavioral toxicology}

All tests were performed between $\mathrm{ZT}_{1}$ and $\mathrm{ZT}_{6}$. Locomotor activity (total distance, rearing, and center time) was recorded over $30 \mathrm{~min}$ in $40 \times 40 \mathrm{~cm}$ photocell activity monitors, as previously described [3]. Y-maze spontaneous alternations, a measure of spatial working memory, were scored over $5 \mathrm{~min}$ as described [22]. Arm dimensions were 35 (I) $\times 10$ (w) $\times 25$ (h) $\mathrm{cm}$. Social interaction was assessed by pairing with a novel female mouse in a neutral environment (clean cage). Social investigation (allo-sniffing) and aggression (fighting, stand-offs, tail rattling) were scored blinded over $5 \mathrm{~min}$ from videos. Beam walking, a measure of motor strength and coordination, was assessed over $2 \mathrm{~min}$, as described [23]. Male sexual behaviors were assessed over $15 \mathrm{~min}$ after introduction of an estrous female into the home cage of a singlehoused male. Mounting number and duration, sexual interest (ano-genital sniffing), and social investigation (allo-sniffing) were scored blinded from videos.

5-HTP absolute bioavailability

5 -HTP was administered orally $(60 \mathrm{mg} / \mathrm{kg})$ or intravenously $(20 \mathrm{mg} / \mathrm{kg})$ and tail blood samples for 5-HTP quantitation were collected at 5, 15, 30, 60, 90, 120, 180, and $240 \mathrm{~min}$. 5-HTP Plasma area under the curve (AUC) was computed. Absolute bioavailability (F): $\frac{A U C_{\text {Oral }}}{A U C_{\text {IV }}} \times \frac{\text { Dose }_{\text {IV }}}{\text { Dose }_{\text {oral }}}$

Test sequences

Mice were tested in a pre-specified sequence before final euthanasia and tissue collection (Table S2).

Monoamine analysis

5- $\mathrm{HT}_{\text {Tissue, }}$ 5-HIAA ${ }_{\text {Tissue, }} 5-\mathrm{HTP}_{\text {Tissue, }}$ and 5-HTP ${ }_{\text {Plasma }}$ were quantified by high-performance liquid chromatography (HPLC) with electrochemical detection as described $[3,18]$.

mRNA quantitation by real-time PCR

mRNA levels were determined as described [24]. In brief, RNA was extracted, reverse transcribed to CDNA, and CDNA levels 
A

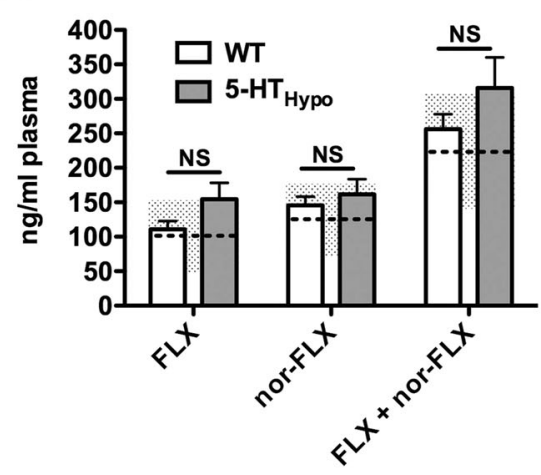

C

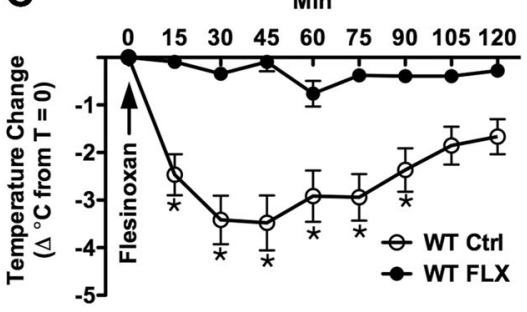

$\mathbf{E}$

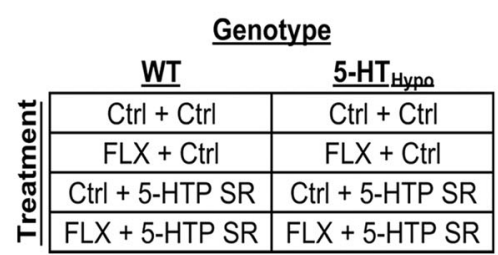

B
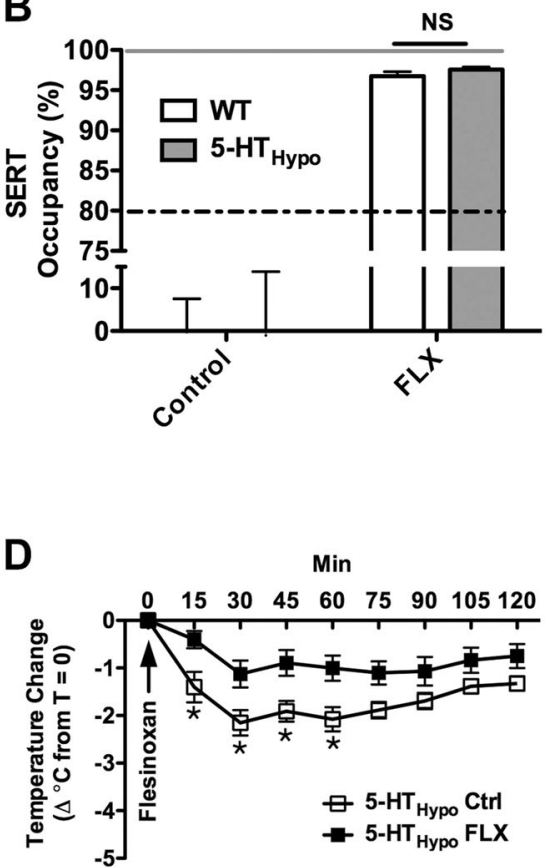

$\mathbf{F}$

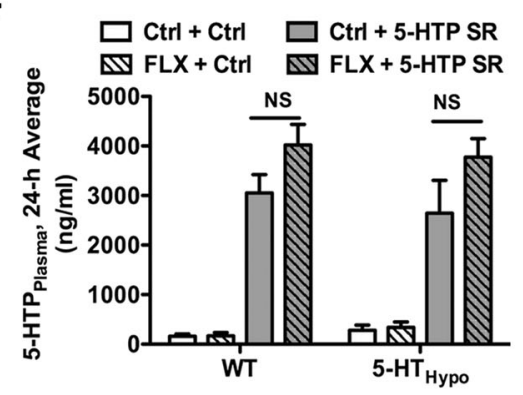

G

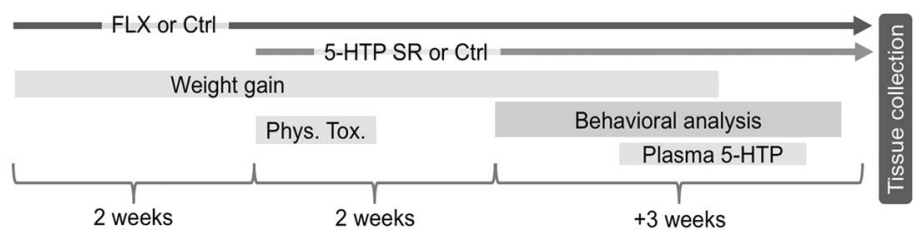

Fig. 1 Clinically relevant fluoxetine and oral 5-HTP SR treatments. a Average plasma fluoxetine and nor-fluoxetine levels (measured at ZT $\mathrm{T}_{0}$ ) after 2 weeks of oral fluoxetine $(4 \mathrm{mg} / \mathrm{kg} /$ day) are similar to clinical averages. Dotted lines = clinical averages; shaded areas $=$ clinical standard deviation [reported in [25]] (WT, $n=11 ; 5-\mathrm{HT}_{\text {Hypo, }} n=10$ ). b Clinically relevant SERT occupancy after fluoxetine treatment (WT, $n=8 ; 5-\mathrm{HT}_{\mathrm{Hypo}}$ $n=8)$. c, d As in humans, fluoxetine blunts the hypothermic response to a $5-\mathrm{HT}_{1 \mathrm{~A}}$ agonist (flesinoxan, $\left.3.3 \mathrm{mg} / \mathrm{kg}, \mathrm{I.P}.\right)\left(\mathrm{WT}, n=6-8 ; 5-\mathrm{HT} \mathrm{Hypo}_{\mathrm{H}}\right.$ $n=8-9)$. e Treatment groups. f Average 5-HTP Plasma levels over $24 \mathrm{~h}$ (WT, $\left.n=8-10 ; 5-\mathrm{HT}_{\mathrm{Hypo}}, n=6-9\right)$. g Treatment and timeline schematic. Statistics: $(\mathbf{a}, \mathbf{b})$ t-test. $(\mathbf{c}, \mathbf{d})$ Two-way RM-ANOVA, followed by Bonferroni post hoc test. f Two-way ANOVA, followed by Bonferroni post-hoc test. ${ }^{*} p<0.05$

quantified by real-time PCR. Primers: Glyceraldehydes 3-phosphate dehydrogenase (GAPDH): 5'-CAA CTT TGG CAT TGT GGA AGG-3' and 5'-GTG GAT GCA GGG ATG ATG TT-3'. Brain-derived neurotrophic factor (BDNF): 5'-CAA TGC CGA ACT ACC CAA-3' and 5'-AAC ATA AAT CCA CTA TCT TCC CC-3'. Fibroblast growthfactor 2 (FGF-2): $5^{\prime}-\mathrm{CCT}$ TGC TAT GAA GGA AGA TGG A-3' and $5^{\prime}-$ CCG TGA CCG GTA AGT ATT GTA G-3'.

Statistical analysis

Data were analyzed with unpaired Student's t-test, one-way analysis of variance (ANOVA), two-way ANOVA, or two-way repeated measures (RM)-ANOVA, as appropriate, using Prism statistical software version 5.0 f (GraphPad Software, La Jolla, CA, USA). When significant factor effects or factor interactions were detected, analysis of variance was followed by Bonferroni's posthoc test, or, when comparison to the untreated Ctrl + Ctrl group was most relevant, Dunnett's post hoc test. Our focus was the effect of adjunctive oral 5-HTP SR, not tph2 genotype. Therefore, WT and $5-\mathrm{HT}_{\text {Hypo }}$ data were analyzed separately. Data are presented as mean \pm standard error of mean (SEM). Detailed statistical data including $F$-values and degrees of freedom are presented in Table S1.

\section{RESULTS}

The SSRI paradigm recapitulates a clinical scenario

To evaluate the translational fidelity of our SSRI paradigm,

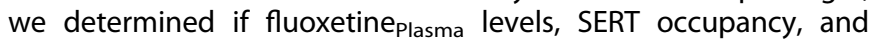


$5-\mathrm{HT}_{1 \mathrm{~A}}$ agonist hypothermia corresponded to a therapeutic scenario. In both WT and $5-\mathrm{HT}_{\text {Hypo }}$ mice, fluoxetine Plasma $_{\text {and }}$

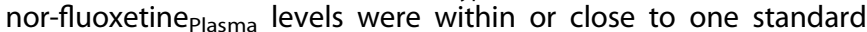
deviation of mean therapeutic levels (Fig. 1a) [25]. SERT occupancy was above $80 \%$, but did not reach saturation (Fig. 1b), as observed in SSRI-treated patients [26]. As previously reported [18], $5-\mathrm{HT}_{1 \mathrm{~A}}$ agonist hypothermia was reduced in $5-\mathrm{HT}_{\text {Hypo }}$ compared to WT mice (Fig. 1c, d). As in humans [27], fluoxetine blunted the hypothermic response. The blunting was less in $5-\mathrm{HT}_{\mathrm{Hypo}}$ mice, probably reflecting that chronic fluoxetine elevates $5-\mathrm{HT}_{\mathrm{Ext}}$ only minimally in $5-\mathrm{HT}_{\text {Hypo }}$ mice $[3,24]$.

Oral 5-HTP SR elevates 5-HTP Plasma

During oral 5-HTP SR treatment, the average $24-\mathrm{h} 5-\mathrm{HTP}_{\text {Plasma }}$ levels were $\sim 3000 \mathrm{ng} / \mathrm{ml}$ (Fig. 1f). There were no significant treatment differences between groups of mice treated with oral 5HTP SR.

Oral 5-HTP SR markedly elevates brain 5-HT synthesis and tissue levels

Oral 5-HTP SR elevated 5- $\mathrm{HT}_{\text {Tissue }}$ in the frontal cortex, hippocampus, and nucleus accumbens, irrespective of fluoxetine cotreatment. In 5-HT Hypo mice, oral $5-\mathrm{HTP}$ SR restored $5-\mathrm{HT}_{\text {Tissue }}$ to WT levels in all brain regions (Fig. 2a, d, g). Oral 5-HTP SR also

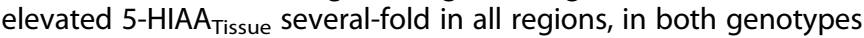

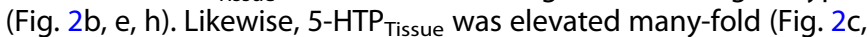
f). Lastly, in the nucleus accumbens we also quantified $D_{\text {Tissue }}$ and found no treatment effects (Fig. 2i).

Adjunctive oral 5-HTP SR causes no adverse effects

We assessed the effects of oral 5-HTP SR on safety measures related to physiology, motor activity, motor coordination, working memory, social behaviors, and sexual behaviors (Fig. 3). Oral 5-HTP $\mathrm{SR}$-alone or adjunctive to fluoxetine-did not cause diarrhea or mild seizures (head-twitches), and did not affect body weight gain, spontaneous activity, motor coordination (beam walking), spatial working memory (Y-maze alternations), social interest (allosniffing), or sexual interest (male ano-genital sniffing of an estrous female). We also scored mounting sexual behavior and observed no apparent effects of oral 5-HTP SR, although low levels of mounting limited this assessment (Fig. S1). In WT mice only, fluoxetine modestly decreases forward locomotion (Fig. 3e, k) and, surprisingly, enhanced spatial working memory (Fig. $3 \mathrm{~m}$ ).

Oral adjunctive 5-HTP IR causes significant adverse effects Adjunctive oral 5-HTP IR $100 \mathrm{mg} / \mathrm{kg}$ caused strong diarrhea in both WT and $5-\mathrm{HT}_{\text {Hypo }}$ mice, and mild seizures (head-twitches) in $5-\mathrm{HT}_{\text {Hypo }}$ mice (Fig. 4b, c). Adjunctive 5-HTP IR transiently elevated 5-HTP Plasma to $4000-6000 \mathrm{ng} / \mathrm{ml}$ (Fig. 4d, e).

Adjunctive oral 5-HTP SR augments the effects of SSRI treatment in 5 -HT-sensitive behaviors

We tested the behavioral effects of oral 5-HTP SR in several paradigms commonly responsive to enhanced brain 5-HT function. In novelty suppressed feeding, in both $\mathrm{WT}$ and $5-\mathrm{HT}_{\text {Hypo }}$ mice, fluoxetine treatment alone had no effect. Oral 5-HTP SR decreased latency to feed, and there was a statistically significant interaction between fluoxetine and oral 5-HTP SR. We performed post hoc analysis to compare the three treatment groups individually to untreated controls. In WT mice, fluoxetine + oral 5-HTP SR treatment significantly decreased feeding latency compared to untreated control. In 5-HT $\mathrm{H}_{\text {Hyo }}$ mice, both oral 5-HTP SR alone and fluoxetine + oral 5-HTP SR significantly decreased feeding latency compared to untreated control (Fig. 5a). In marble burying, in both
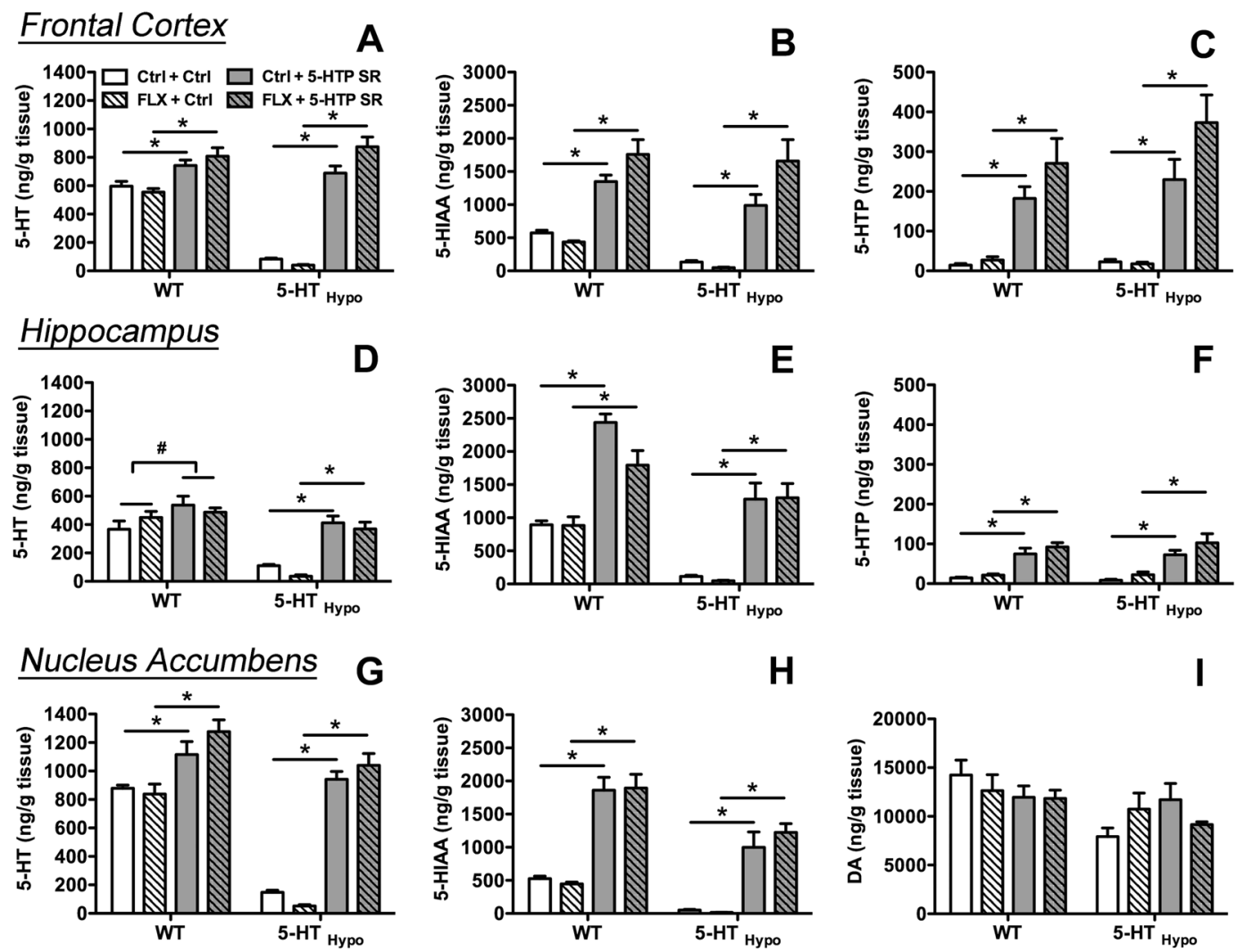

Fig. 2 Oral 5-HTP SR elevates brain 5-HT synthesis, tissue levels and metabolism, and does not affect DA levels. a-c Frontal cortex 5-HT Tissue, 5-HIAA Tissue, $_{\text {and } 5-H T P}$ Tissue levels (WT, $n=8-10 ; 5-\mathrm{HT}_{\text {Hypo, }} n=7-9$ ). d-f Hippocampal 5-HT Tissue, 5-HIAA Tissue, and 5-HTP $_{\text {Tissue }}$ levels (WT, $\left.n=11-12 ; 5-\mathrm{HT}_{\mathrm{Hypo}}, n=9-13\right)$. g-i Nucleus accumbens $5-\mathrm{HT}_{\text {Tissue, }}, 5-\mathrm{HIAA}_{\text {Tissue, }}$ and $\mathrm{DA}_{\text {Tissue }}$ levels $(\mathrm{WT}, n=6-10 ; 5-\mathrm{HT} \mathrm{Hypo}, n=7-9)$. Statistics: two-way ANOVA, followed by Bonferroni post hoc test. ${ }^{*} p<0.05$ 
A
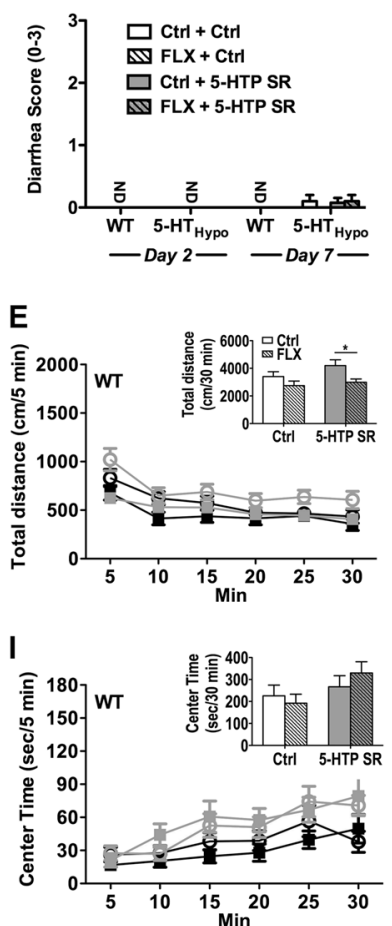

M

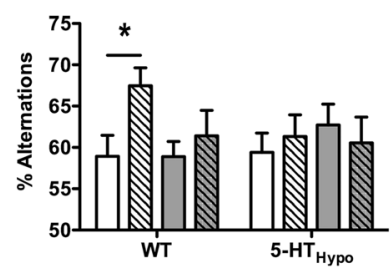

B

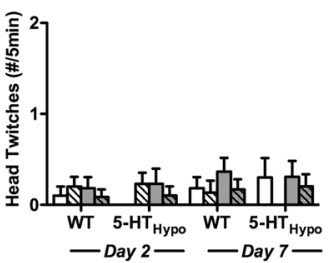

F

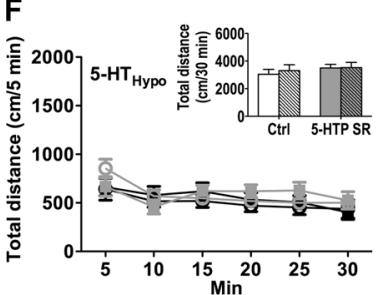

J K

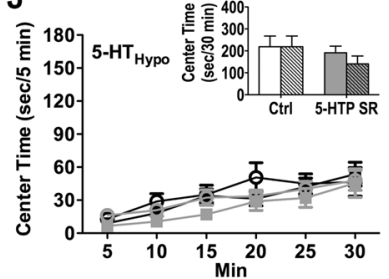

$\mathbf{N}$

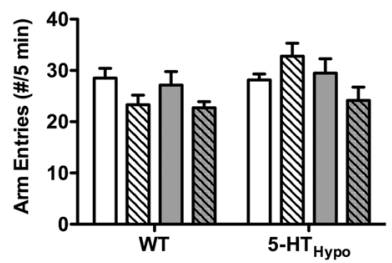

C

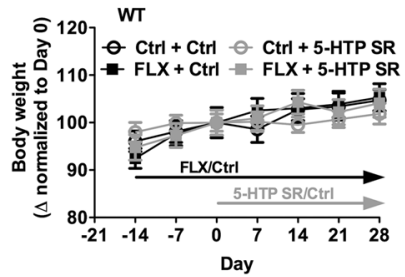

G

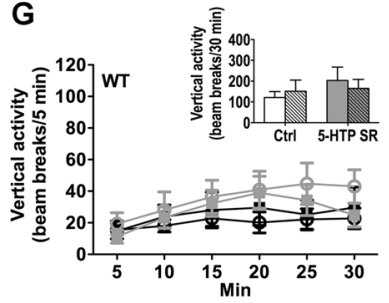

K

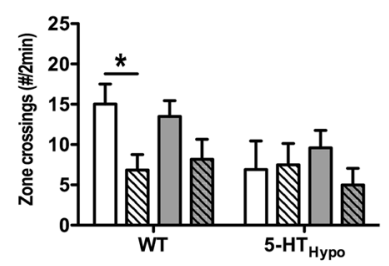

0

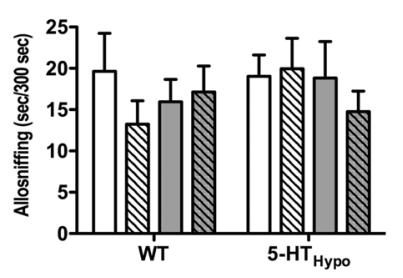

D

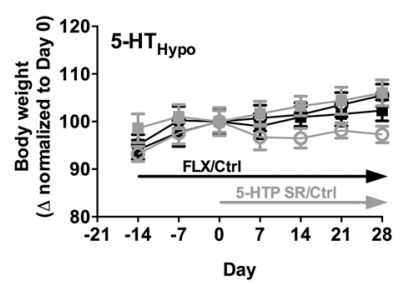

H

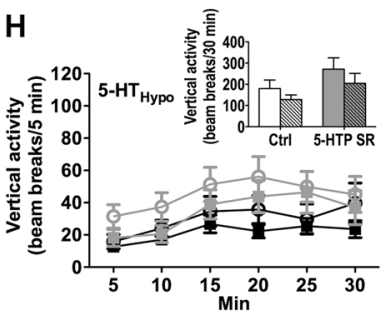

L

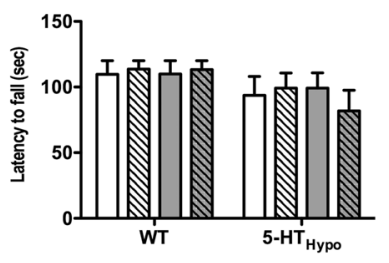

$\mathbf{P}$

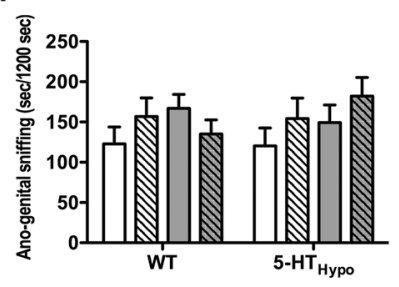

Fig. 3 Adjunctive oral 5-HTP SR causes no physiological or behavioral adverse effects. a Diarrhea and b head-twitch (mild seizures) quantitation at day 2 and 7 after commencement of oral 5-HTP SR treatment (WT, $n=11-15 ; 5-\mathrm{HT}_{\mathrm{Hypo}}, n=10-13$ ). $\mathbf{c}$, d) Body weight gain from 14 days prior to 28 days after commencement of oral 5 -HTP SR treatment (WT, $n=11-15 ; 5-\mathrm{HT}_{\mathrm{Hypo}}, n=10-13$ ). Spontaneous activity e, $\mathrm{f}$ total distance, $\mathbf{g}, \mathbf{h}$ vertical activity, and $\mathbf{i}$, $\mathbf{j}$ center time (WT, $n=11-15 ; 5-\mathrm{HT}_{\mathrm{Hypo}}, n=10-13$ ). Beam walking $\mathbf{k}$ zone crossings and $\mathbf{I}$ latency to fall (cut-off $120 \mathrm{~s}$ ) (WT, $n=11-15 ; 5-\mathrm{HT}_{\mathrm{Hypo}}, n=10-13$ ). Y-maze $\mathbf{m}$ spontaneous alternations $(50 \%=$ chance) and $\mathbf{n}$ arm entries (activity control parameter) (WT, $\left.n=15-21 ; 5-\mathrm{HT}_{\mathrm{Hypo}}, n=14-21\right)$. o Social interaction with a novel same-sex mouse $\left(\mathrm{WT}, n=11-14 ; 5-\mathrm{HT} \mathrm{Hypo}_{1}, n=9-13\right)$. $\mathbf{p}$ Male sexual interest for an estrous female introduced into the home cage (WT, $\left.n=9-13 ; 5-\mathrm{HT}_{\mathrm{Hypo}}, n=9-11\right)$. Statistics: two-way ANOVA, followed by Bonferroni post hoc test. ${ }^{*} p<0.05$

WT and 5-HT $\mathrm{H}_{\text {Hypo }}$ mice, both fluoxetine and oral 5-HTP SR inhibited marble burying behavior. In WT mice, there was a statistically significant interaction between fluoxetine and oral 5-HTP SR. In both WT and 5-HT $\mathrm{T}_{\text {Hypo }}$ mice, post hoc analysis found that only the fluoxetine + oral 5-HTP SR treatment groups significantly inhibited marble burying, as compared to untreated controls (Fig. 5b). In the forced swim test, the only effect was that fluoxetine increased immobility (Fig. S2A), a not uncommon finding [28]. In the tail suspension test, we observed no treatments effects (Fig. S2B), again, for fluoxetine, not an uncommon finding [29].

Under 5-HT deficiency, adjunctive oral 5-HTP SR augments SSRIinduced gene transcription of neurotrophic factors

In WT mice, we found that fluoxetine decreased hippocampal BDNF and FGF2 mRNA levels (Fig. 5c, d). In contrast, in 5-HT mice both fluoxetine and oral 5-HTP SR elevated hippocampal BDNF and FGF2 mRNA levels. Post-hoc testing found that only the fluoxetine + oral 5-HTP SR treatment group significantly elevated BDNF and FGF2 mRNA levels in $5-\mathrm{HT}_{\text {Hypo }}$ mice as compared to untreated controls (Fig. 5c, d). In the nucleus accumbens there were no treatments effects (Fig. 5e, f).

\section{5-HTP bioavailability}

Oral administration of 5-HTP $60 \mathrm{mg} / \mathrm{kg}$ produced a slightly larger $5-$ HTP $_{\text {Plasma }}$ AUC compared to IV administration of $5-\mathrm{HTP} 20 \mathrm{mg} / \mathrm{kg}$ (Fig. S3A). Adjusting for dose, absolute bioavailability was computed to $F=40 \%$ (Fig. S3B).

Oral 5-HTP SR has minimal effects on jejunal $5-\mathrm{HT}_{\text {Tissue }}$ levels In WT mice fluoxetine modestly decreased while oral 5-HTP SR modestly increased $5-\mathrm{HT}_{\text {Tissue }}$ in the jejunum. In $5-\mathrm{HT}_{\text {Hypo }}$ mice a similar trend was apparent, but it did not reach statistical significance. In both genotypes, levels of 5 -HIAA ${ }_{\text {Tissue }}$ were manyfold increased, reflecting that a substantial fraction of oral 5-HTP SR is metabolized via the 5-HT pathway in the intestine (Fig. S4).

\section{DISCUSSION}

5-HTP has shown therapeutic promise in mood and other CNS disorders. But the pharmacokinetics of native 5-HTP (IR) is too rapid for general drug therapy. Here, using translationally optimized mouse paradigms, we tested the hypothesis that SR delivery would substantially improve the therapeutic properties of 5-HTP. 


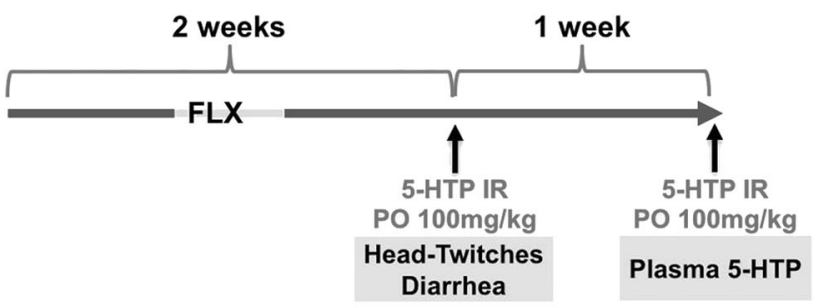

B

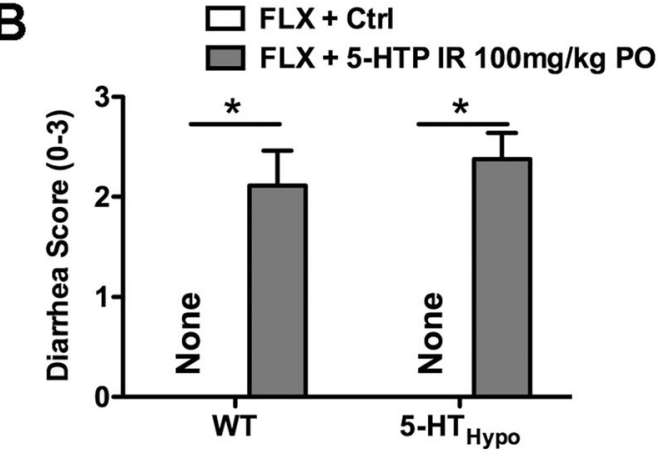

C
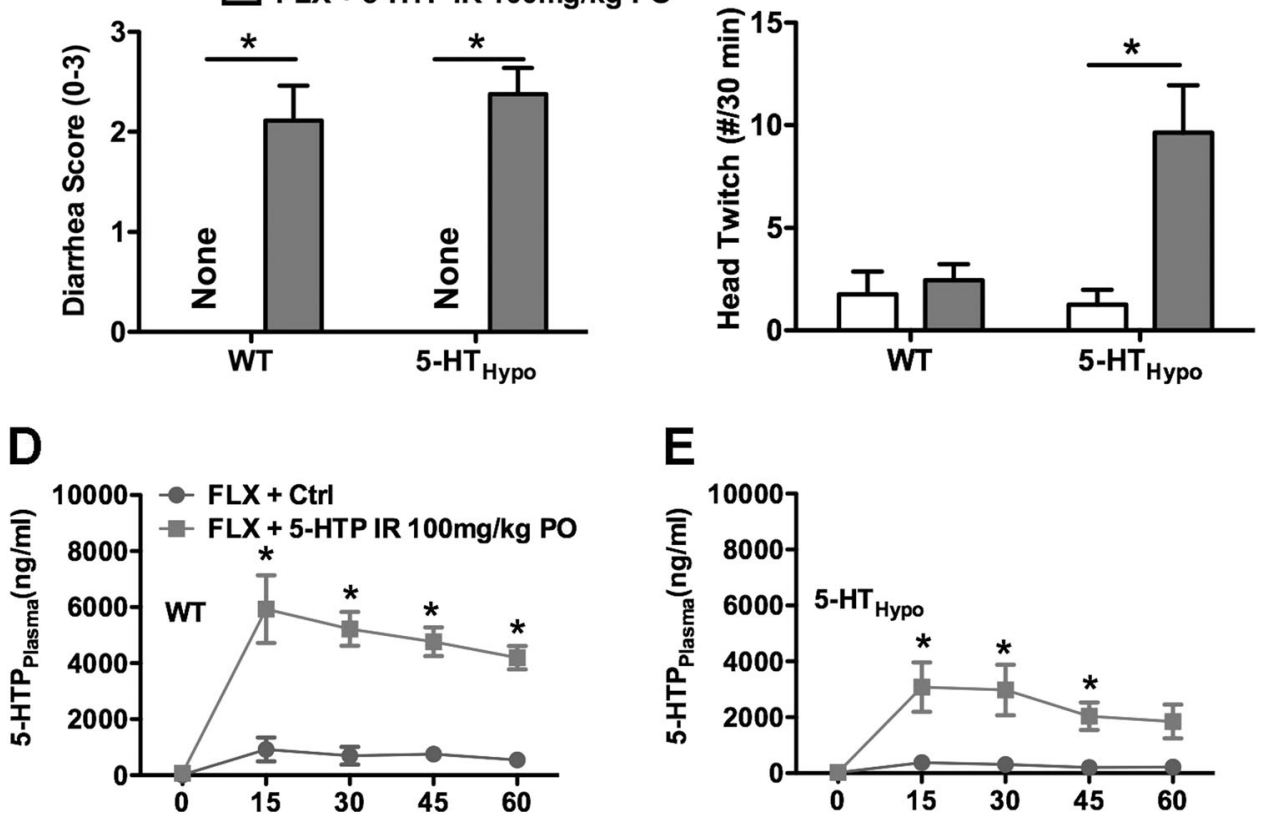

Fig. 4 A one-tenth dose of adjunctive oral 5-HTP IR, as compared to oral 5-HTP SR, causes adverse effects. a Treatment timeline schematic. b Diarrhea, and c head-twitch (mild seizures) quantitation (WT, $n=8-9 ; 5-\mathrm{HT}_{\mathrm{Hypo}}, \mathrm{n}=8-9$ ). $\mathbf{d}$, e 5-HTP Plasma levels (5-HTP IR $100 \mathrm{mg} / \mathrm{kg}$ PO at $T=0 \mathrm{~min}$ ) (WT, $n=8 ; 5-\mathrm{HT}_{\text {Hypo, }} n=7$ ). Statistics: $\mathbf{b}, \mathbf{c} t$-test. d, e Two-way RM-ANOVA, followed by Bonferroni post hoc test. ${ }^{*} p<0.05$

We report that oral 5-HTP SR can safely elevate plasma 5-HTP to pharmacologically active levels, can enhance brain 5-HT synthesis and levels, can safely be combined with SSRI treatment, and can augment the SSRI pharmacological effect. Additionally, oral 5-HTP SR has more pronounced pro-serotonergic effects under conditions of brain $5-\mathrm{HT}$ deficiency.

The present study has advantages and limitations. Advantages include chronic oral administration, clinically relevant SSRI exposure, assessment of SSRI and 5-HTP SR effects under normal and 5-HT-deficient conditions, and a comprehensive multi-domain screen for adverse effects. One limitation is the inherent difficulty of emulating oral SR delivery in mice. Dietary administration provides a reasonable approach, as drug delivery is distributed throughout the $24-\mathrm{h}$ day. Another limitation is that brain $5-\mathrm{HT}_{\mathrm{Ext}}$ could not be quantified, i.e. with microdialysis. The required invasive procedures would alter dietary consumption, which would alter drug delivery, rendering $5-\mathrm{HT}_{\mathrm{Ext}}$ data uninterpretable in the context of the main body of data presented. Further, for this first oral proof-of-concept study, due to resource limitations, we studied only one oral 5-HTP SR dose and used female mice only in most paradigms. However, such limitations do not impact the overall ramifications, that SR delivery markedly improves the drug properties of oral 5-HTP.

Oral 5-HTP SR produced average steady state 5 -HTP Plasma $_{\text {levels }}$ of $\sim 3000 \mathrm{ng} / \mathrm{ml}$. In humans, after 5-HTP administration, reported 5-HTP Plasma levels sufficient to enhance indices of brain 5-HT function ranges from several hundreds to low thousands $\mathrm{ng} / \mathrm{ml}$
$[4,12,30]$. Thus, the $5-\mathrm{HTP}_{\text {Plasma }}$ levels observed after oral 5-HTP $\mathrm{SR}$ are consistent with enhancement of brain 5-HT function. After oral 5-HTP IR, $C_{\text {Max }}$ occurred at the first time-point, $15 \mathrm{~min}$, indicating rapid absorption of 5-HTP from the intestine, as is also observed in humans [12].

In drug discovery, good safety is equally important to therapylike pharmacokinetics and pharmacodynamics. In rodents, 5-HTP $\mathrm{IR}$, in medium to high parenteral bolus doses (10-200 mg/ $\mathrm{kg})$, can induce mild seizures (head-twitch), diarrhea, and motor anomalies in mice, toxic effects exacerbated by SSRI co-treatment [31-33]. Here we report that oral 5 -HTP SR, in a dose of $1000 \mathrm{mg} / \mathrm{kg} / \mathrm{day}$, alone or as adjunctive to SSRI treatment, causes no discernable adverse events in a comprehensive toxicology screen assessing physiological, motoric, behavioral, and cognitive parameters. Importantly, we detected no signs of serotonin syndrome. In contrast, adjunctive oral 5-HTP IR-at $100 \mathrm{mg} / \mathrm{kg}$, a tenth of the dose of 5-HTP SR-caused diarrhea in both genotypes and headtwitches in $5-\mathrm{HT}_{\text {Hypo }}$ mice. This stark difference in safety between 5-HTP SR and IR parallels our previous finding investigating the pre-clinical pharmacology and safety of parenteral 5-HTP SR and IR [3]. Interestingly, rapid onset diarrhea and other Gl events are among the most common and significant safety findings with oral 5-HTP IR in human trials [34]. Likely, the rapid onset adverse effects of 5-HTP IR can be accounted for by a rapid spike in

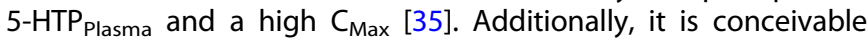
that the two weeks pre-treatment with SSRI prior to adding oral 5-HTP SR contributed to the absence of overt adverse events with 
A

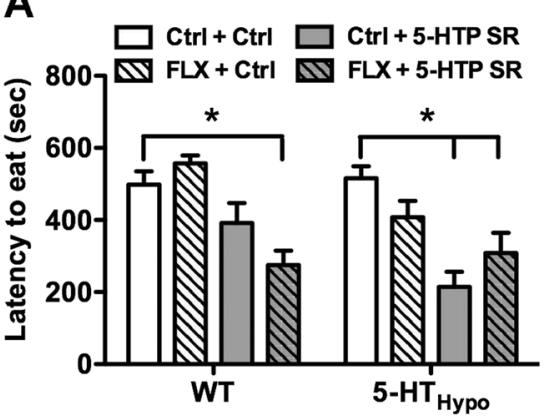

C

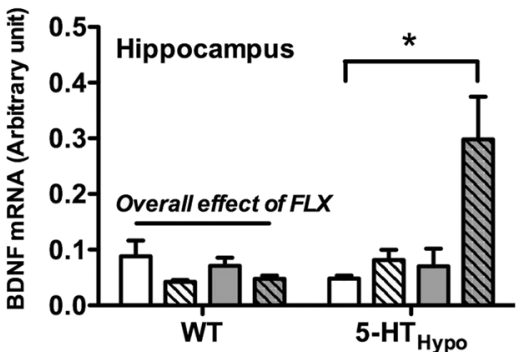

E

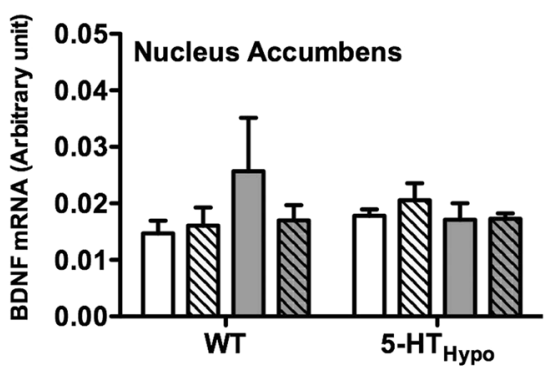

B

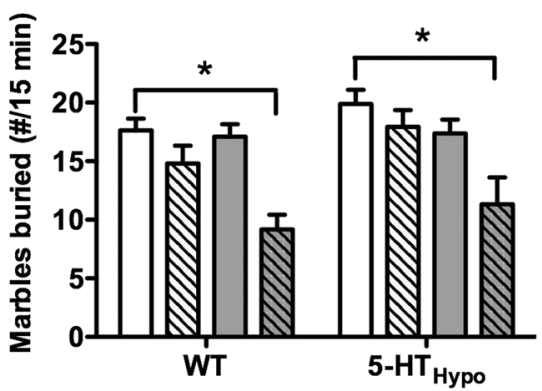

D

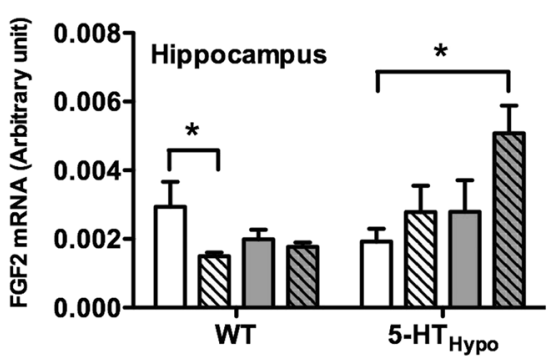

F

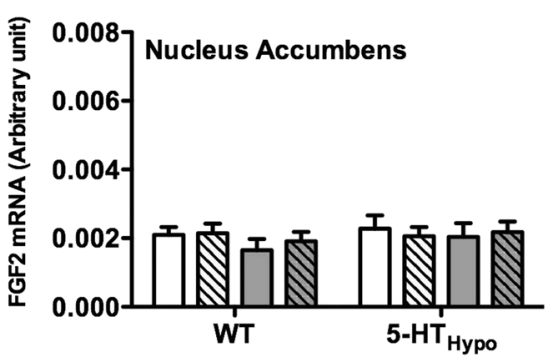

Fig. 5 Adjunctive oral 5-HTP SR augments 5-HT-sensitive behaviors and induces growth factor mRNA transcription. a Novelty suppressed feeding, latency to eat a peanut chip (WT, $n=17-24 ; 5-\mathrm{HT}_{\text {Hypo, }} n=17-21$ ). b Marble burying, marbles buried in $15 \mathrm{~min}$ (WT, $n=9-12$; $\left.5-\mathrm{HT}_{\mathrm{Hypo}}, n=9-11\right)$. c BDNF and d FGF2 mRNA in the hippocampus (WT, $n=7-10 ; 5-\mathrm{HT}_{\mathrm{Hypo}}, n=6-8$ ). e BDNF and $\mathbf{f}$ FGF2 mRNA in the nucleus accumbens (WT, $n=7-10 ; 5-\mathrm{HT}_{\mathrm{Hypo}}, n=6-8$ ). Statistics: two-way ANOVA, followed by Dunnett's post hoc test. Brackets indicate significant difference from $\mathrm{Ctrl}+\mathrm{Ctrl}$ group. ${ }^{*} p<0.05$

the combined treatment, by ensuring that 5-HT function was enhanced step-wise.

We assessed the pharmacodynamic effects of oral 5-HTP SR, alone or adjunctive to SSRI treatment, on the monoamine, behavioral, and gene transcription levels. In both genotypes, oral 5-HTP SR produced a large elevation in brain 5-HTP, demonstrating that a substantial proportion of orally administered 5-HTP reaches the brain. In WT mice, oral 5-HTP SR only moderately elevated $5-\mathrm{HT}_{\text {Tissue, }}$ i.e. $5-\mathrm{HT}$ neuronal storage. However, this may not represent the magnitude of enhancement of brain 5-HT function, as our previous report found that parenteral 5-HTP SR in WT mice doubled neuronal $5-\mathrm{HT}$ release (i.e. $5-\mathrm{HT}_{\mathrm{Ext}}$ ) despite not altering brain $5-\mathrm{HT}_{\text {Tissue }}$ levels. An explanation could be that 5-HT neuronal storage in WT mice at baseline is already close to capacity. Consistent with this notion, in $5-\mathrm{HT}_{\text {Hypo }}$ mice, where $5-\mathrm{HT}$ neuronal storage is reduced by $80 \%$ [19], oral 5-HTP SR strongly elevated $5-\mathrm{HT}_{\text {Tissue, }}$ restoring levels to WT levels. In both genotypes, 5-HIAA ${ }_{\text {Tissue }}$ was many-fold elevated. This indicates greatly enhanced flow through the 5-HT metabolic pathway, which is generally associated with increased 5-HT function. As previously reported with parenteral $5-\mathrm{HTP}$ SR [3], DA $\mathrm{A}_{\text {Tissue }}$ was unaffected by oral 5-HTP SR. Thus, oral 5-HTP SR caused a marked enhancement of brain 5-HT synthesis, levels, and metabolism, and seemingly without interfering with storage of other monoamines.

Only the combined treatment with SSRI and oral 5-HTP SR reliably enhanced 5-HT-sensitive behaviors and hippocampal neurotropic gene transcription. These findings could reflect human and animal findings, ours and others, that SSRIs and 5-HTP synergize in enhancing 5-HT function $[3,4,36]$. In contrast to in the hippocampus, no treatment affected nucleus accumbens neurotrophic gene transcription. The reason for this regiondependency is not clear. However, it is note-worthy that nucleus accumbens BDNF appears to a mediator of stress responses rather than of antidepressant effects [37].

As explained above, methodological constraints inherently precluded directly quantifying brain $5-\mathrm{HT}_{\mathrm{Exx}}$. However, it is justified to surmise that adjunctive oral 5-HTP SR substantially elevated brain $5-\mathrm{HT}_{\text {Ext }}$. First, previously we reported that $5-\mathrm{HTP}$ Plasma levels of $\sim 1000 \mathrm{ng} / \mathrm{ml}$, after parenteral 5-HTP SR $100 \mathrm{mg} / \mathrm{kg} /$ day, corresponded to one- to several-fold elevations in brain $5-\mathrm{HT}_{\mathrm{Ext}}$, whether above baseline or above the effect caused by SSRI treatment [3]. In the present study, oral 5-HTP SR $1000 \mathrm{mg} / \mathrm{kg} / \mathrm{day}$ produced $5-\mathrm{HTP}_{\text {Plasma }}$ levels of $\sim 3000 \mathrm{ng} / \mathrm{ml}$, three times higher than parenteral 5-HTP SR. Second, oral 5-HTP SR produced substantially more robust elevation of brain $5-\mathrm{HT}_{\text {Tissue }}$ than did 
parenteral 5-HTP SR. Third, adjunctive oral 5-HTP SR impacted 5-HT-sensitive behaviors and gene transcription, indicating functionally active $5-\mathrm{HT}_{\text {Ext }}$ elevation.

The long half-life of fluoxetine and the active metabolite in rodents makes fluoxetine ideal for modeling SSRI therapy [38], as in human therapy SSRI exposure fluctuates minimally. We observed fluoxetine $e_{\text {Plasma }}$ levels, SERT occupancy, and a blunting of $5-\mathrm{HT}_{1 \mathrm{~A}} \mathrm{R}$ agonist hypothermia corresponding to that observed during human SSRI therapy $[25,27,39]$. Thus, our SSRI regimen recapitulated a clinical scenario, which is critical for a translational study.

Similar to other reports using therapeutically relevant SSRI regimens, we observed minimal effects of SSRI alone on 5-HTsensitive behaviors and gene transcription $[40,41]$. These minimal pharmacodynamic effects may reflect human and rodent data that clinically relevant SSRI regimens elevate $5-\mathrm{HT}_{\mathrm{Ext}}$ only moderately $[42,43]$. In mice, higher fluoxetine doses, $10-20 \mathrm{mg} /$ $\mathrm{kg} /$ day, typically have more pronounced pharmacodynamic, e.g. behavioral, neurotrophic, effects [24, 44]. However, these higher

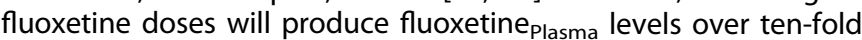
higher than therapeutic levels $[20,45]$. At such supra-clinical levels fluoxetine significantly engages multiple transporters, receptors, and ion channels, not engaged during a therapeutic scenario [46]. Such off-target effects would have confounded the present study, which aimed to focus on 5-HT function and aimed to maximize translational fidelity.

\section{CONCLUSION}

The present report demonstrates, in animal models, that SR delivery markedly and to an unexpected degree improves the therapeutic properties of oral 5-HTP. The present data should be appreciated in the context of the large body of clinical data suggesting that 5-HTP has therapeutic potential but pharmacokinetics incompatible with general therapy, and appreciated in the context of our previous report on parenteral 5-HTP SR [3]. A 5-HTP SR drug could be particularly relevant as an adjunctive to augment SSRI therapy, e.g. depression refractory to SSRI therapy [2], and in conditions associated with 5-HT deficiency, e.g. impulse control disorders and suicidality [47]. CNS drug concepts can take decades to mature from initial clinical findings to established therapy $[48,49]$. In the case of $5-\mathrm{HTP}$, only recently has drug delivery technologies become available to enable a 5-HTP SR drug [35]. Altogether, clinical and preclinical data suggest that a 5-HTP SR drug could represent a new treatment option for mood and other CNS disorders treatable with serotonergic drugs.

\section{FUNDING AND DISCLOSURE}

This work was supported in part by grants from the National Institutes of Health MH79201 and MH60451 (MGC). BDS was the recipient of a Minority Supplement award from the National Institutes of Health (MH79201-03S1). JPRJ was the recipient of an individual grant from The Lundbeck Foundation of Denmark. Support from the Lennon Family Foundation to MGC for earlier foundational work is greatly appreciated. MGC and JPRJ are inventors on issued and pending patents in relation to the therapeutic use of 5-HTP SR. MGC and JPRJ are shareholders in Evecxia Inc., a company founded to develop and commercialize 5-HTP SR therapeutics. The remaining authors have nothing to disclose.

\section{ADDITIONAL INFORMATION}

Supplementary Information accompanies this paper at (https://doi.org/10.1038/ s41386-019-0400-1).

Publisher's note: Springer Nature remains neutral with regard to jurisdictional claims in published maps and institutional affiliations.

\section{REFERENCES}

1. Davidson J, Sjoerdsma A, Loomis LN, Udenfriend S. Studies with the serotonin precursor, 5-hydroxytryptophan, in experimental animals and man. J Clin Invest. 1957;36:1594-9.

2. Jacobsen JP, Krystal AD, Krishnan KR, Caron MG. Adjunctive 5-Hydroxytryptophan slow-release for treatment-resistant depression: clinical and preclinical rationale. Trends Pharmacol Sci. 2016a;37:933-44.

3. Jacobsen JP, Rudder ML, Roberts W, Royer EL, Robinson TJ, Oh A, et al. SSRI augmentation by 5 -hydroxytryptophan slow release: mouse pharmacodynamic proof of concept. Neuropsychopharmacology. 2016b;41:2324-34.

4. Sargent PA, Williamson DJ, Cowen PJ. Brain 5-HT neurotransmission during paroxetine treatment. Br J Psychiatry: J Ment Sci. 1998;172:49-52.

5. Nardini M, De Stefano R, lannuccelli M, Borghesi R, Battistini N. Treatment of depression with L-5-hydroxytryptophan combined with chlorimipramine, a double-blind study. Int J Clin Pharm Res. 1983;3:239-50.

6. van Hiele LJ. 1-5-Hydroxytryptophan in depression: the first substitution therapy in psychiatry? The treatment of 99 out-patients with 'therapy-resistant' depressions. Neuropsychobiology. 1980;6:230-40.

7. van Praag HM. Serotonin precursors in the treatment of depression. Adv Biochem Psychopharmacol. 1982;34:259-86.

8. Trouillas P, Brudon F, Adeleine P. Improvement of cerebellar ataxia with levorotatory form of 5-hydroxytryptophan. A double-blind study with quantified data processing. Arch Neurol. 1988;45:1217-22.

9. Cangiano C, Ceci F, Cascino A, Del Ben M, Laviano A, Muscaritoli M, et al. Eating behavior and adherence to dietary prescriptions in obese adult subjects treated with 5-hydroxytryptophan. Am J Clin Nutr. 1992;56:863-7.

10. Caruso I, Sarzi Puttini P, Cazzola M, Azzolini V. Double-blind study of 5hydroxytryptophan versus placebo in the treatment of primary fibromyalgia syndrome. J Int Med Res. 1990;18:201-9.

11. Das YT, Bagchi M, Bagchi D, Preuss HG. Safety of 5-hydroxy-L-tryptophan. Toxicol Lett. 2004;150:111-22.

12. Gijsman HJ, van Gerven JM, de Kam ML, Schoemaker RC, Pieters MS, Weemaes M, et al. Placebo-controlled comparison of three dose-regimens of 5hydroxytryptophan challenge test in healthy volunteers. J Clin Psychopharmacol. 2002;22:183-9.

13. Lowe SL, Yeo KP, Teng L, Soon DK, Pan A, Wise SD, et al. L-5-Hydroxytryptophan augments the neuroendocrine response to a SSRI. Psychoneuroendocrinology. 2006;31:473-84.

14. Croom KF, Wellington K. Modified-release nifedipine: a review of the use of modified-release formulations in the treatment of hypertension and angina pectoris. Drugs. 2006;66:497-528.

15. Zhang $\mathrm{Y}$, Britto MR, Valderhaug $\mathrm{KL}$, Wedlund PJ, Smith RA. Dextromethorphan: enhancing its systemic availability by way of low-dose quinidine-mediated inhibition of cytochrome P4502D6. Clin Pharmacol Ther. 1992;51:647-55.

16. Hyman SE. Revolution stalled. Sci Transl Med. 2012;4:155cm111.

17. Insel TR. Next-generation treatments for mental disorders. Sci Transl Med. 2012;4:155ps119.

18. Jacobsen JP, Siesser WB, Sachs BD, Peterson S, Cools MJ, Setola V, et al. Deficient serotonin neurotransmission and depression-like serotonin biomarker alterations in tryptophan hydroxylase 2 (Tph2) loss-of-function mice. Mol psychiatry. 2012b;17:694-704.

19. Beaulieu JM, Zhang X, Rodriguiz RM, Sotnikova TD, Cools MJ, Wetsel WC, et al. Role of GSK3 beta in behavioral abnormalities induced by serotonin deficiency. Proc Natl Acad Sci USA. 2008;105:1333-8.

20. Siesser WB, Sachs BD, Ramsey AJ, Sotnikova TD, Beaulieu JM, Zhang X, et al. Chronic SSRI Treatment Exacerbates Serotonin Deficiency in Humanized Tph2 Mutant Mice. ACS Chem Neurosci. 2013;4:84-88.

21. Bachmanov AA, Reed DR, Beauchamp GK, Tordoff MG. Food intake, water intake, and drinking spout side preference of 28 mouse strains. Behav Genet. 2002;32:435-43.

22. Jacobsen JP, Redrobe JP, Hansen $\mathrm{HH}$, Petersen $\mathrm{S}$, Bond $\mathrm{CT}$, Adelman JP, et al. Selective cognitive deficits and reduced hippocampal brain-derived neurotrophic factor mRNA expression in small-conductance calcium-activated $\mathrm{K}+$ channel deficient mice. Neuroscience. 2009;163:73-81.

23. Jacobsen JP, Weikop P, Hansen HH, Mikkelsen JD, Redrobe JP, Holst D, et al. SK3 K +channel-deficient mice have enhanced dopamine and serotonin release and altered emotional behaviors. Genes Brain Behav. 2008;7:836-48.

24. Sachs BD, Jacobsen JP, Thomas TL, Siesser WB, Roberts WL, Caron MG. The effects of congenital brain serotonin deficiency on responses to chronic fluoxetine. Transl Psychiatry. 2013;3:e291.

25. Amsterdam JD, Fawcett J, Quitkin FM, Reimherr FW, Rosenbaum JF, Michelson D, et al. Fluoxetine and norfluoxetine plasma concentrations in major depression: a multicenter study. Am J psychiatry. 1997;154:963-9.

26. Meyer JH, Wilson AA, Sagrati S, Hussey D, Carella A, Potter WZ, et al. Serotonin transporter occupancy of five selective serotonin reuptake inhibitors at different 
Slow-release delivery enhances the pharmacological properties of oral... JP Jacobsen et al.

2090

doses: an [11C]DASB positron emission tomography study. Am J psychiatry. 2004;161:826-35.

27. Lerer B, Gelfin Y, Gorfine M, Allolio B, Lesch KP, Newman ME. 5-HT1A receptor function in normal subjects on clinical doses of fluoxetine: blunted temperature and hormone responses to ipsapirone challenge. Neuropsychopharmacology. 1999;20:628-39.

28. Lucki I, Dalvi A, Mayorga AJ. Sensitivity to the effects of pharmacologically selective antidepressants in different strains of mice. Psychopharmacology. 2001;155:315-22.

29. Benton CS, Miller BH, Skwerer S, Suzuki O, Schultz LE, Cameron MD, et al. Evaluating genetic markers and neurobiochemical analytes for fluoxetine response using a panel of mouse inbred strains. Psychopharmacology. 2012;221:297-315.

30. Magnussen I, Van Woert MH. Human pharmacokinetics of long term 5-hydroxytryptophan combined with decarboxylase inhibitors. Eur J Clin Pharm. 1982;23:81-6.

31. Pascual D, Alsasua A, Goicoechea C, Martin MI. The involvement of 5-HT3 and 5 -HT4 receptors in two models of gastrointestinal transit in mice. Neurosci Lett. 2002;326:163-6.

32. Sanchez C, Kreilgaard M. R-citalopram inhibits functional and 5-HTP-evoked behavioural responses to the SSRI, escitalopram. Pharmacol, Biochem, Behav. 2004;77:391-8.

33. Schmid CL, Bohn LM. Serotonin, but not N-methyltryptamines, activates the serotonin $2 \mathrm{~A}$ receptor via a ss-arrestin2/Src/Akt signaling complex in vivo. J Neurosci. 2010;30:13513-24.

34. Turner EH, Loftis JM, Blackwell AD. Serotonin a la carte: supplementation with the serotonin precursor 5-hydroxytryptophan. Pharm Ther. 2006;109:325-38.

35. Thombre AG. Assessment of the feasibility of oral controlled release in an exploratory development setting. Drug Disco Today. 2005;10:1159-66.

36. Perry KW, Fuller RW. Extracellular 5-hydroxytryptamine concentration in rat hypothalamus after administration of fluoxetine plus L-5-hydroxytryptophan. J Pharm Pharm. 1993;45:759-61.

37. Berton O, McClung CA, Dileone RJ, Krishnan V, Renthal W, Russo SJ, et al. Essential role of BDNF in the mesolimbic dopamine pathway in social defeat stress. Science. 2006;311:864-8.

38. Holladay JW, Dewey MJ, Yoo SD. Pharmacokinetics and antidepressant activity of fluoxetine in transgenic mice with elevated serum alpha-1-acid glycoprotein levels. Drug Metab Dispos: Biol fate Chem. 1998;26:20-4.
39. Owens MJ, Krulewicz S, Simon JS, Sheehan DV, Thase ME, Carpenter DJ, et al. Estimates of serotonin and norepinephrine transporter inhibition in depressed patients treated with paroxetine or venlafaxine. Neuropsychopharmacology. 2008;33:3201-12.

40. Miro X, Perez-Torres S, Artigas F, Puigdomenech P, Palacios JM, Mengod G. Regulation of CAMP phosphodiesterase mRNAs expression in rat brain by acute and chronic fluoxetine treatment. An in situ hybridization study. Neuropharmacology. 2002;43:1148-57.

41. Oh JE, Zupan B, Gross S, Toth M. Paradoxical anxiogenic response of juvenile mice to fluoxetine. Neuropsychopharmacology. 2009;34:2197-207.

42. Haahr ME, Fisher PM, Jensen CG, Frokjaer VG, Mahon BM, Madsen K, et al. Central 5-HT4 receptor binding as biomarker of serotonergic tonus in humans: a [11C] SB207145 PET study. Mol Psychiatry. 2014;19:427-32.

43. Wegener G, Bandpey Z, Heiberg IL, Mork A, Rosenberg R. Increased extracellular serotonin level in rat hippocampus induced by chronic citalopram is augmented by subchronic lithium: neurochemical and behavioural studies in the rat. Psychopharmacology. 2003;166:188-94.

44. Santarelli L, Saxe M, Gross C, Surget A, Battaglia F, Dulawa S, et al. Requirement of hippocampal neurogenesis for the behavioral effects of antidepressants. Science. 2003;301:805-9.

45. Hodes GE, Hill-Smith TE, Suckow RF, Cooper TB, Lucki I. Sex-specific effects of chronic fluoxetine treatment on neuroplasticity and pharmacokinetics in mice. J Pharm Exp Ther. 2010;332:266-73.

46. Werling LL, Keller A, Frank JG, Nuwayhid SJ. A comparison of the binding profiles of dextromethorphan, memantine, fluoxetine and amitriptyline: treatment of involuntary emotional expression disorder. Exp Neurol. 2007;207:248-57.

47. Jacobsen JP, Medvedev IO, Caron MG. The 5-HT deficiency theory of depression: perspectives from a naturalistic 5-HT deficiency model, the tryptophan hydroxylase 2Arg439His knockin mouse. Philos Trans R Soc Lond B Biol Sci. 2012a;367: 2444-59.

48. Berman RM, Marcus RN, Swanink R, McQuade RD, Carson WH, Corey-Lisle PK, et al. The efficacy and safety of aripiprazole as adjunctive therapy in major depressive disorder: a multicenter, randomized, double-blind, placebo-controlled study. J Clin Psychiatry. 2007;68:843-53.

49. Chen JW, Borgelt LM, Blackmer AB. Epidiolex (Cannabidiol): a new hope for patients with dravet or lennox-gastaut syndromes. Ann Pharmacother. 2019. 1060028018822124. 